\title{
Microbiological Profile of Some Ghanaian Herbal Preparations-Safety Issues and Implications for the Health Professions
}

\author{
Joseph A. Ampofo", Anthonia Andoh, Wilhermina Tetteh, Mohammed Bello \\ Microbiology Section, Environmental Biology and Health Division, Water Research Institute, Accra, Ghana \\ Email: jaampofo@yahoo.com
}

Received May 3, 2012; revised June 12, 2012; accepted June 25, 2012

\begin{abstract}
Thirty-one herbal preparations produced and sold on the Ghanaian market were randomly purchased from sales outlets and analyzed for their microbiological quality by testing for the presence of total coliform bacteria, faecal coliform bacteria, and total heterotrophic bacteria count. Also tested for was detection of pathogenic bacteria such as the Salmonella spp. and Clostridium spp. Opportunistic bacterial pathogens (Aeromonas spp., Enterococcus spp. and Pseudomonas spp.) and mould were also tested for. The herbal preparations tested came from different processing companies and included those labeled as suitable for treating arthritis, asthma, anaemia, diabetes mellitus, epilepsy, cough, hypertension, dysmenorrhoea, malaria, urine retention and loss of appetite. Aliquots of the various herbal products were cultured on various selective media. Eight (8) of the products showed the presence of all microorganism analyzed for including the pathogenic ones and are recommended not be used. Five (5) of the products did not have any microorganism present. Eleven (11) products showed the presence of only total heterotrophic bacteria and the values ranged from 1 to $94 \mathrm{cfu}$ per ml. These two groups of total of sixteen (16) products can be used without any microbiological risk. Another three (3) products showed presence of only total heterotrophic bacteria but the values ranged from 118 to $1648 \mathrm{cfu}$ per ml. Majority of the herbal preparations showed the presence of pathogenic bacteria. These three products may pose danger to the user can be used with caution. None of the herbal products recorded the presence of Enterococcus spp.
\end{abstract}

Keywords: Herbal Preparations; Bacterial Pathogens; Opportunistic Pathogens; Mould

\section{Introduction}

Herbal medicine-also called botanical medicine or phytomedicine-refers to using a plant's seeds, berries, roots, leaves, bark, or flowers for medicinal purposes [1]. Herbalism has a long tradition of use outside of conventional medicine. It is becoming more mainstream as improvements in analysis and quality control along with advances in clinical research show the value of herbal medicine in the treating and preventing disease.

The World Health Organization (WHO) estimates that four billion people (about 80 percent of the world population) use herbal medicine for some aspect of primary health care [2].

Plants had been used for medicinal purposes long before recorded history. Ancient Chinese and Egyptian papyrus writings describe medicinal uses for plants as early as 3000 BC. Indigenous cultures (such as African and Native American) used herbs in their healing rituals, while others developed traditional medical systems (such

"Corresponding author. as Ayurveda and Traditional Chinese Medicine) in which herbal therapies were used [3]. Researchers found that people in different parts of the world tended to use the same or similar plants for the same purposes [4].

In the early 19th century, when chemical analysis first became available, scientists began to extract and modify the active ingredients from plants. Later, chemists began making their own version of plant compounds and, over time, the use of herbal medicines declined in favor of drugs. Almost one fourth of pharmaceutical drugs are derived from botanicals [5].

The use of herbal medicine has been reported to be on the increase in many developing and industrialized countries [6,7]. It is known that between $65 \%$ and $80 \%$ of the world's population use herbal medicine as their primary form of healthcare $[8,9]$. The WHO directive encourages developing countries to supplement their health programmes with traditional herbal preparations provided they are proven to be non-toxic [10]. Some of the commonly used Nigerian medicinal plants, Morinda lucida [Oruwo (root)], Azadirachta indica [Dongoyaro (leaf)] 
and Alstonia boonei [Ahun (bark)] have been demonstrated to possess analgesic, anti-inflammatory and antipyretic properties [11]. Thus, the use of herbal medicines has been documented to play significant roles in the management of both minor and major illnesses [12-14].

The sophistication of herbal remedies used around the world varies with the technological advancement of countries that produce and use them. These remedies range from medicinal teas and crude tablets used in traditional medicine to concentrated, standardized extracts produced in modern pharmaceutical facilities and used in modern medical systems under a physician's supervision.

The use of herbal supplements has increased dramatically over the past 30 years. Herbal supplements are classified as dietary supplements by the US Dietary Supplement Health and Education Act (DSHEA) of 1994. That means herbal supplements-unlike prescription drugs - can be sold without being tested to prove they are safe and effective $[1,15,16]$. However, herbal supplements must be made according to good manufacturing practices.

The most commonly used herbal supplements in the US include echinacea (Echinacea purpurea and related species), St. John's wort (Hypericum perforatum), ginkgo (Ginkgo biloba), garlic (Allium sativum), saw palmetto (Serenoa repens), ginseng (Panax ginseng, or Asian ginseng and Panax quinquefolius, or American ginseng), goldenseal (Hydrastis canadensis), valerian (Valeriana officinalis), chamomile (Matricaria recutita), feverfew (Tanacetum parthenium), ginger (Zingiber officinale), evening primrose (Oenothera biennis), and milk thistle (Silybum marianum) [17,18].

Often, herbs may be used together because the combination is more effective and may have fewer side effects. Health care providers must take many factors into account when recommending herbs, including the species and variety of the plant, the plant's habitat, how it was stored and processed, and whether or not there are contaminants (including heavy metals and pesticides).

Herbal remedies are the staple of medical treatment in many developing countries. Herbal preparations are used for virtually all minor ailments. Visits to Western-trained doctors or prescription pharmacists are reserved for life-threatening or hard-to-treat disorders.

Herbal medicine is used to treat many conditions, such as asthma, eczema, premenstrual syndrome, rheumatoid arthritis, migraine, menopausal symptoms, chronic fatigue, irritable bowel syndrome, and cancer, among others [19-22]. Herbal supplements are best taken under the guidance of a trained health care provider. Some common herbs and their uses are discussed below.

- Ginkgo (Ginkgo biloba) has been used in traditional medicine to treat circulatory disorders and enhance memory.

- Kava kava (Piper methysticum) is said to elevate mood, enhance well being and contentment, and produce a feeling of relaxation.

- Saw palmetto (Serenoa repens) is used by more than 2 million men in the United States for the treatment of benign prostatic hyperplasia (BPH), a non cancerous enlargement of the prostate gland.

- St. John's wort (Hypericum perforatum) is well known for its antidepressant effects.

- Valerian (Valeriana officinalis) is a popular alternative to commonly prescribed medications for sleep problems because it is considered to be both safe and gentle.

- Echinacea preparations (from Echinacea purpurea and other Echinacea species) may improve the body's natural immunity.

In recent years a significant worldwide increase has been reported in the general use of complementary and alternative medicine (CAM) [23-26]. Studies on the attitudes of Western doctors to complementary medicine have been carried out in European and North American countries [8,27-30] and it has been shown that complementary medicine has become more important in terms of dissatisfaction with modern Western medicine (conventional medicine) or with medical economics [8]. A study on the attitude of doctors to traditional herbal medicine conducted in Africa (Ghana) showed that $75 \%$ of the population of Ghana depended on traditional herbal medicine for their healthcare [31,32]. Comparatively, Western pharmaceutical medicine is more successful in developed countries than in the underdeveloped African countries and a host of factors account for this. Amongst such factors are the high cost of pharmaceutical medicines, hospitals and medical facilities which are not accessible to many, and overcrowding of patients in clinics and hospitals. Use of CAM has therefore become more popular in these areas.

It has earlier been projected that integrative medicine, which is defined as the blending of conventional and herbal/natural/complementary medicines and/or therapies, with the aim of using the most appropriate of either or both modalities to care for the patient holistically [33] would make healthcare much more effective.

The Centre for Scientific Research into Plant Medicine (CSRPM) was established in 1975 by the Government of Ghana in recognition of the pioneering work of Dr. Oku Ampofo, a Ghanaian allopathic medical practitioner. Today, CSRPM has become a leading research institution in Africa that has made Research and Development of herbal medicines its core business. Mist Tonica, one of the several herbal remedies the Centre for Scientific Research into Plant Medicine (CSRPM) has produced, has been used as an effective treatment for anaemia and loss of appetite for over 30 years at CSRPM.

Herbal medicines are prepared from a variety of plant 
materials such as leaves, stems, stem bark, roots, root bark, fruits and flowers. These are harvested mainly from the wild and at various stages of development. Plant raw materials harvested at various stages of development contain active constituents that may also be at different stages of biosynthesis. While young plants may contain only precursors, over-aged plants may contain degradation products of the active ingredients. For instance, monkshood is harmless when young but when mature, it contains highly toxic alkaloids.

Active ingredients are usually unequally distributed among the different parts of the plants, active constituents are concentrated in a single part of the plant. For instance, the invigorating constituents of ginseng are concentrated in only the roots. In some other plants, different types of active ingredients are found in different parts of the plant. For instance, the fruits of the orange tree contain invigorating substances while sedative substances are located in the flowers.

Due to inherent variations in the concentrations of active constituents, which sometimes make it difficult to establish how effective herbal medicines are, a lot of skeptisms have been associated with the use of herbal medicine These observations, and others, bring to the fore the need for standardization of herbal medicines. Without standardization, herbal medicines, as they are now prepared in Ghana, are likely to contain varying levels of active constituents. Some medicines may have high levels of active constituents and thus lead to overdose while others may have little or no active constituents at all, and may at best be described as placebos.

Standardization should begin with cultivation of medicinal plants, and herbal medicine manufacturers should be encouraged to use cultivated medicinal plant raw materials in the production of their medicines. Cultivated plants offer several advantages in terms of standardizetion. The plants can be cultivated in homogeneous climatic and soil conditions and can be harvested at the right time (i.e. age and time of collection). Plant material processing should also be standardized.

Harvested raw materials need to be dried at controlled time and temperature to ensure stability of the active constituents. Processed raw materials could then be stored under appropriate conditions. The manufacturer of the final product should also set and follow standard operating procedures and also be guided by Good Manufacturing Practice to ensure production of quality herbal medicines and make herbal medicines more acceptable both locally and internationally.

Commercial herbal preparations are available in several different forms on the Ghanaian market. They include bulk herbs, teas, tinctures, fluid extracts, and tablets or capsules. Infusions are typically used for delicate herbs, leaves and fresh tender plants. Preparing an infu- sion is much like making a cup of tea. Water is brought just to a boil and then poured over an herb (or combination of herbs), it is covered and allowed to sit/steep for 10 - 15 minutes or so. It can be prepared in the drinking cup (by just pouring the heated water over the herb in the cup) or by dropping the herb into the pot which the water was heated in.

Decoctions are usually the method of choice when working with tougher and more fibrous plants, barks and roots (and which have water soluble chemicals). Instead of just steeping it in hot water, the plant material is boiled for a longer period of time to soften the harder woody material and release its active constituents.

Depending on the type of plant material used, strong decoctions are prepared in two general ways. The first involves boiling the mixture longer. This is usually indicated when working with larger woody pieces of bark. Longer boiling time, up to 2 hours or more, is sometimes necessary to break down, soften, and extract the larger pieces. Alternatively, when smaller woody pieces are used yet a stronger remedy is wanted, the decoction is prepared as above (boiling 20 minutes), then it is allowed to sit/soak overnight before straining out the herb.

A tincture is an alcohol and water extract which is used when plants have active chemicals that are not very soluble in water, and/or when a larger quantity is prepared for convenience and wanted for longer term storage. Many properly prepared plant tinctures can last several years or more without losing potency. The percentage of alcohol usually helps determine its shelf-life: the more alcohol used, the longer the shelf life. Sometimes the percentage of alcohol and water is unique to the herbs that are used as some active ingredients are more soluble in alcohol and others more soluble in water. Since this method uses a higher ratio of plant to liquid and helps concentrate the chemicals through the use of alcohol, dosages needed for tinctures are usually much less than infusions and decoctions. Average dosages for tinctures are about 1 - 2 milliliters (about 30 to 60 drops) two to three times daily. The tincture can be placed directly in the mouth for immediate absorption, or placed in a small amount of water or juice.

Macerations preparation is certainly the easiest. The fresh or dried plant material is simply covered in cool water and soaked overnight. The herb is strained out and the liquid is taken. Normally this is used for very tender plants and/or fresh plants, or those with delicate chemicals that might be harmed by heating or which might be degraded in strong alcohol.

Globally, herbal remedies have been researched under rigorous controls and have been approved by the governments of technologically advanced nations. The scientific validation is good to excellent, and the history of clinical use is even stronger. Many phytomedicines have 
been used by thousands of physicians in their practices and are consumed under medical supervision by tens of millions of people.

In the developing world, herbs used for medicinal purposes are "crude drugs." These are unprocessed herbsplants or plant parts, dried and used in whole or cut form. Herbs are prepared as teas (sometimes as pills or capsules) for internal use and as salves and poultices for external use. Most developing countries have minimal regulation and oversight.

Since the effectiveness and the value of most herbs are greatest when the plants are fresh, the best preparations are usually those prepared from freshly gathered herbs. Next best are preparations made from herbs, which have been well preserved by proper drying and storage. Some plants, however, should be used only dried or in professional preparations to avoid or minimize detrimental effects.

But even the best plant materials can be ruined if one uses the wrong kind of process in preparing the remedies. The choice depends primarily on the identity of the plant, the plant parts being used, the elements to be extracted (if any), the form in which the remedy will be taken or applied, and the effect to be achieved.

Basic to the use of medicinal herbs in many societies is the practice of using whole, unrefined plant material. The material may be leaves, buds, flowers, bark, or roots, separately or in combination. In some cases an herbal remedy is a complex mixture of many plants. There is an age-old belief that whole-plant medicines have fewer dangerous side effects and provide a more balanced physiological action than plant-derived pharmaceutical drugs whose single ingredient has been isolated, concentrated, and packaged as a pill or liquid.

Herbs and herbal preparations generally are self-administered. Often they are purchased through native herbalists who prescribe one or more herbs or preparations on the basis of medical and health approaches that often include concepts of attaining balance in the client's body, psychology, and spirit. Consequently, it is often difficult to assess the relative value of herbal remedies versus prescription drugs on a one-to-one basis.

Methods currently utilized in evaluating herbs and their extracts include organoleptic, microscopic, physical, chemical/physical, and biological. Organoleptic analysis involves the application of sight, odour, taste, touch, and occasionally even sound, to identify the plant. Organoleptic analysis represents the simplest, yet the most human, form of analysis. Microscopic evaluation is indispensable in the initial identification of herbs, as well as in identifying small fragments of crude or powdered herbs, and in detection of adulterants (e.g. insects, animal faeces, mould, fungi, etc.) as well as identifying the plant characteristic tissue features [34].

Most standardized extracts are currently made in Europe under strict guidelines set forth by individual members of the European Economic Council (EEC) as well as those proposed by the EEC. Included are guidelines for acceptable levels of impurities such as bacterial counts, pesticides, residual solvents, heavy metals, and product stability.

Ghana today has a dual system of medical practice that recognizes both traditional and modern medical practices in law and promotes their co-existence in order to reach the greatest number of citizens (http://www.unep-wcmc. org/species/plants/ghana.htm). Traditional medicine, for instance, plays a very important role in Ghana where approximately $70 \%$ of the population makes use of the services. These services are often affordable and accessible to the vast rural populace and therefore serve as a forerunner in the primary medical care of the population. The nation has an extremely rich biodiversity and rich tradition of plant medicine in various forms and has an enormous number of indigenous medicinal plants. Each village has its traditional practitioner who uses local plant remedies and in many cases ritual and no doubt non-plant medicine as well.

Opinions about the safety, efficacy, and appropriateness of medicinal herbs vary widely among medical and health professionals in countries where herbal remedies are used. Some countries' professionals accept historical, empirical evidence as the only necessary criterion for herbal medicine's efficacy. Others would ban all herbal remedies as dangerous or of questionable value.

Herbal preparations in Ghana range from individual one-product, home-made product, to family-size and occasionally large scale production where the products are distributed and sold in Chemical and Pharmacy shops in the country.

Improvements in analytical methods have led to improvements in harvesting schedules, cultivation techniques, storage, activity, stability of active compounds, and product purity. All of these gains have resulted in tremendous improvements in the quality of herbal preparations now available.

Currently, in the developed countries, numerous standardized fulfill requirements for marketing as drugs. These extracts have typically gone through many thorough quality control steps.

Recent chemical analysis of commercially available Feverfew (Tanacetum parthenium) and Taheebo (Tahebuia avallanedae) for active components, parthenolide and lapachol, respectively, have also shown need for concern [34]. Analysis of over 35 different commercial preparations of Feverfew indicated a wide variation in the amounts of parthenolide in commercial preparations. The majority of products samples contained no parthenolide whatsoever, or only traces. Additionally, analysis of 
12 commercial sources of Taheebo could identify lapachol (in trace amounts) in only one product.

The widespread disregard for quality control in the health food industry has tarnished the reputation of many important medicinal herbs. Without proper quality control, there is no assurance that the herb contained in the bottle is the same as what is stated on the outside label.

Quality control is a term that refers to processes involved in maintaining the quality of validity of a manufactured product. Regardless of the form of herbal preparation, some degree of quality control should exist. Currently there is no organization or government body in Ghana that certifies an herb as labeled correctly.

Currently it is doubtful if herbal preparation producers in Ghana adhere to complete quality control and good manufacturing procedures including microscopic, physiccal, chemical/physical, and biological analyses. Assessment of the safety and efficacy of these preparations is an important issue for the health professions. This study focuses on the safety of some of these preparations; the issue of their efficacy is not addressed.

\section{Methods}

\subsection{Selection of Samples}

Thirty-one (31) different brands of herbal preparations were purchased from different vendors. The samples were bought from different places in the capital city of Ghana, Accra. This was done to get as many different brands as possible. The herbal preparations included (as claimed by the producers) those for treating anaemia, arthritis, asthma, cough, diabetes mellitus, dysmenorrhoea, epilepsy, hypertension, malaria, urine retention and loss of appetite. The sealed bottles of herbal preparations were cleaned with $70 \%$ ethanol before opening to prevent contamination.

\subsection{Determination of Population of Microbes in the Samples}

This was done by identifying and counting discrete colonies based on the colour of the colonies when the expected microorganism is present. Very small colonies required the use of a Gallenkamp Geiger Counter under a well-lit background.

\subsubsection{Total Coliform Count}

The Multiple Tube Fermentation method [35] was used to determine the levels of total coliform bacteria in each of the herbal preparations. Aliquots of $10 \mathrm{ml}$ of each of the herbal preparation samples were separately used as inocula in ten (10) sets of double strength Lauryl Tryptose Broth in tubes. All tubes that showed heavy growth, with any amount of gas and acidic growth within 24 hours at $37^{\circ} \mathrm{C} \pm 0.5^{\circ} \mathrm{C}$, were confirmed as positive for presence of total coliform using Brilliant green lactose bile broth and incubating at $37^{\circ} \mathrm{C} \pm 0.5^{\circ} \mathrm{C}$ for 48 hours.

\subsubsection{Faecal Coliform Count}

All tubes of the total coliform test that showed heavy growth, with any amount of gas and acidic growth within 48 hours at $37^{\circ} \mathrm{C} \pm 0.5^{\circ} \mathrm{C}$ using Brilliant green lactose bile broth, were inoculated into EC Medium and incubated in water bath at $44.5^{\circ} \mathrm{C} \pm 0.2^{\circ} \mathrm{C}$ for 24 hours.

\subsubsection{Salmonella/Shigella spp}

One milliliter $(1 \mathrm{ml})$ of each of the herbal sample was mixed with molten SS agar (Difco). Inoculated plates were incubated aerobically at $37^{\circ} \mathrm{C}$ for 24 hours. All colonies that showed black colour were counted as positive for Salmonella/ Shigella spp.

\subsubsection{Total Heterotrophic Bacteria}

Viable heterotrophic bacterial populations were determined for all the herbal preparations using the heterotrophic plate count procedure [35] at $37^{\circ} \mathrm{C} \pm 0.5^{\circ} \mathrm{C}$. The low-nutrient medium (NWRI) agar was used. One (1.0) $\mathrm{ml}$ of each sample was mixed with liquefied $\left(45^{\circ} \mathrm{C}\right)$ NWRI agar, in sterile Petri dishes, and the mixture allowed to solidify and incubated for 48 hours. Bacterial colonies, which developed, were counted.

\subsubsection{Clostridium spp. Count}

Ten milliliters $(10 \mathrm{ml})$ of each of the herbal preparation samples were separately pasteurized at $80^{\circ} \mathrm{C}$ for $10 \mathrm{~min}$ utes. $1 \mathrm{ml}$ of each sample was inoculated into molten Yeast Extract Agar (Oxoid) in sterile Petri plates. Inoculated plates were incubated anaerobically at $37^{\circ} \mathrm{C}$ for 48 hours.

\subsubsection{Bacillus spp. Count}

Ten milliliters $(10 \mathrm{ml})$ of each of the herbal preparation samples were separately pasteurized at $80^{\circ} \mathrm{C}$ for $10 \mathrm{~min}-$ utes. One milliliter $(1 \mathrm{ml})$ of each sample was inoculated into molten Yeast Extract Agar (Oxoid) in sterile Petri plates. Inoculated plates were incubated aerobically at $37^{\circ} \mathrm{C}$ for 48 hours.

\subsubsection{Moulds Determination}

One milliliter $(1 \mathrm{ml})$ of each sample was inoculated separately into Neopeptone-glucose-rose Bengal Aureomycin agar [35] in sterile Petri plates. A preparation of $0.05 \mathrm{ml}$ of tetracycline $(1 \mathrm{~g}$ water soluble antibiotic/150 ml distilled water) was added to the molten mixture to check the growth of bacteria. Incubation was at $20^{\circ} \mathrm{C}-22^{\circ} \mathrm{C}$ and plates were counted after 7 days.

\subsubsection{Pseudomonas Counts}

One milliliter $(1 \mathrm{ml})$ of each of the herbal sample was 
mixed with molten Cetrimide agar (Difco). Inoculated plates were incubated aerobically at $37^{\circ} \mathrm{C}$ for 24 hours.

\section{Results}

Thirty-one (31) herbal products were analyzed for their microbiological quality. Out of these thirty-one products twelve (12) showed high levels of total heterotrophic bacteria, ranging from $94 \mathrm{cfu} / \mathrm{ml}$ to $2320 \mathrm{cfu} / \mathrm{ml}$.

Nine (9) of the samples showed the presence of total coliform bacteria. These included one product for treatment of asthma, one cough product, a product for controlling diabetes, one dysmenorrhoea product, one hypertensive product, two products for malaria, and, two products for urinary retention. Eight (8) of these samples showed the presence of thermotolerant coliforms. These included the asthma product, the cough mixture, the diabetes product, dysmenorrhoea product, hypertensive product, the two malaria products, and, one of the urinary retention products.

Products which did not register any indicator organism, and had less than $50 \mathrm{cfu} / \mathrm{ml}$ of total heterotrophic bacteria, included all the two products for appetite, two products for anaemia, two products for arthritis, two other cough mixtures, one other product for diabetes mellitus, four other products for dysmenorrhoea, two other products for hypertension, three other products for malaria, and one other product for urinary retention.

Mould grew significantly in four products showing colonies of between $7 \mathrm{cfu} / \mathrm{ml}$ to $1300 \mathrm{cfu} / \mathrm{ml}$. These products were Asthma Mix B, Epilepsy Mix B, Hypertension Mix A and malaria Mix E.

Dysmenorrhoea Mix A showed significant growth of Clostridium spp. recording $596 \mathrm{cfu} / \mathrm{ml}$. Other three products that showed some growth of Clostridium spp. were Asthma Mix B (7 cfu/ml), Cough Mixture D (7 cfu/ml) and Diabetes Mellitus Mix A (13 cfu/ml).

Pseudomonas spp. was recorded with Hypertension Mix A (23 cfu/ml) and Malaria Mix E (8 cfu/ml).

Bacillus spp. were detected in eight products, howbeit in minute quantities, ranging from $1 \mathrm{cfu} / \mathrm{ml}$ to $22 \mathrm{cfu} / \mathrm{ml}$. The products were Asthma Mix B, Cough Mixture D, Diabetes Mellitus Mix A, Dysmenorrhoea Mix A, Hypertention Mix A, Malaria Mix B, Malaria Mix E and Urinary retention Mix B.

None of the products recorded presence of Enterococcus spp.

Results of the microbial load of the various herbal products as determined are as follows:

\begin{tabular}{|c|c|c|c|c|c|c|c|c|c|}
\hline Sample Identification & $\begin{array}{c}\text { TC } \\
\text { Cfu/100ml }\end{array}$ & FC & $\begin{array}{l}\text { Salmo. } \\
\text { spp. }\end{array}$ & $\begin{array}{l}\text { Pseud.s } \\
\text { spp. }\end{array}$ & $\begin{array}{l}\text { Entero. } \\
\text { Spp. }\end{array}$ & THB & $\begin{array}{l}\text { Clostr. } \\
\text { spp. }\end{array}$ & $\begin{array}{l}\text { Bacillus } \\
\text { spp. }\end{array}$ & Mould \\
\hline 1. Appetite Mix. A & - & - & - & - & - & 17 & - & - & - \\
\hline 2. Appetite Mix. B & - & - & - & - & - & - & - & - & - \\
\hline 3. Anaemia Mix. A & - & - & - & - & - & 10 & - & - & - \\
\hline 4. Anaemia Mix. B & - & - & - & - & - & 7 & - & - & - \\
\hline 5. Arthritis Mix. A & - & - & - & - & - & 3 & - & - & - \\
\hline 6. Arthritis Mix. B & - & - & - & - & - & - & - & - & - \\
\hline 7. Asthma Mix. A & - & - & - & - & - & 1648 & - & - & - \\
\hline 8. Asthma Mix. B & 47 & 16 & 6 & - & - & 1500 & 7 & 6 & 464 \\
\hline 9. Cough Mixture A & - & - & - & - & - & 118 & - & - & - \\
\hline 10. Cough Mixture B & - & - & - & - & - & 94 & - & - & - \\
\hline 11. Cough Mixture C & - & - & - & - & - & 6 & - & - & - \\
\hline 12. Cough Mixture D & 84 & 22 & 12 & - & - & 5 & 7 & 6 & - \\
\hline $\begin{array}{l}\text { 13. Diabetes Mellitus } \\
\text { Mix. A }\end{array}$ & 115 & 40 & 7 & - & - & 340 & 13 & 1 & - \\
\hline $\begin{array}{l}\text { 14. Diabetes Mellitus } \\
\text { Mix. B }\end{array}$ & - & - & - & - & - & 40 & - & - & 1 \\
\hline $\begin{array}{l}\text { 15. Dysmenorrhoea } \\
\text { Mix. A }\end{array}$ & 62 & 10 & - & - & - & 11 & 596 & 22 & - \\
\hline $\begin{array}{l}\text { 16. Dysmenorrhoea } \\
\text { Mix. B }\end{array}$ & - & - & - & - & - & 7 & - & - & - \\
\hline $\begin{array}{l}\text { 17. Dysmenorrhoea } \\
\text { Mix. C }\end{array}$ & - & - & - & - & - & 12 & - & - & - \\
\hline $\begin{array}{l}\text { 18. Dysmenorrhoea } \\
\text { Mix. D }\end{array}$ & - & - & - & - & - & - & - & - & - \\
\hline 19. Epilepsy Mix. A & - & - & - & - & - & 1448 & - & - & - \\
\hline 20. Epilepsy Mix. B & - & - & - & - & - & 556 & - & - & 7 \\
\hline
\end{tabular}




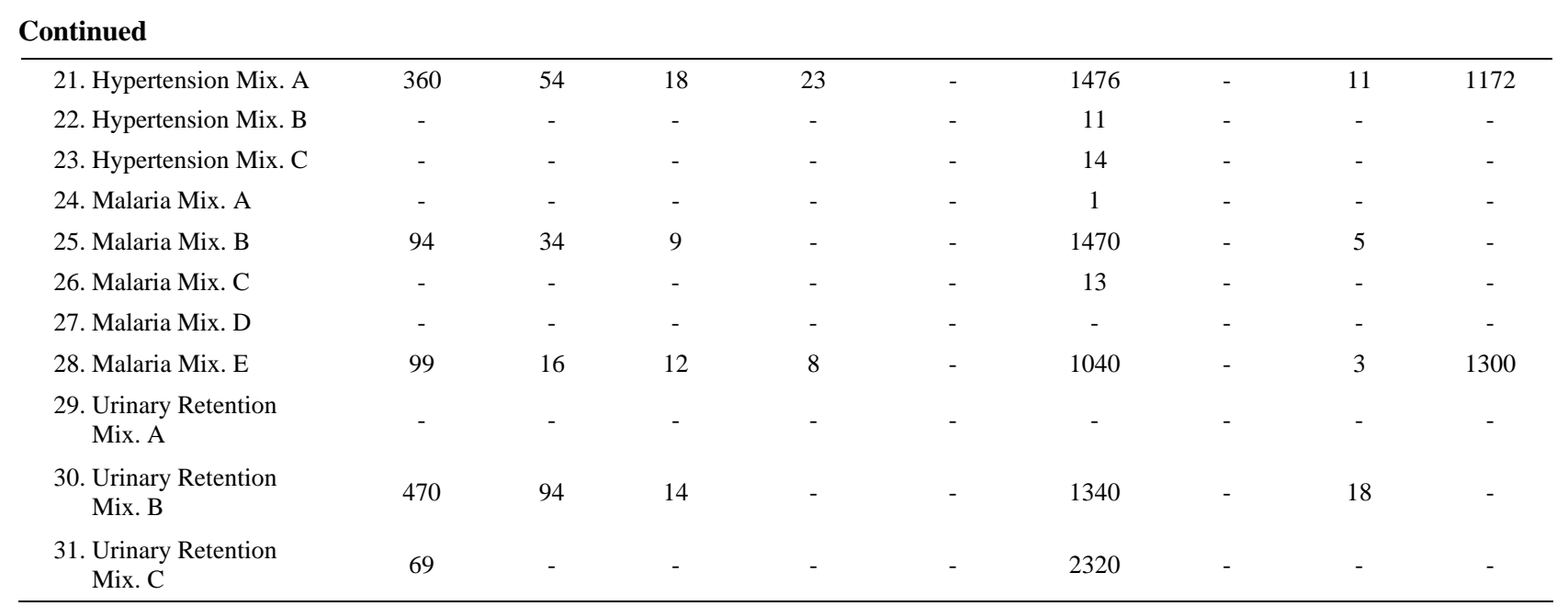

TC = Total coliform bacteria count; FC = Faecal coliform bacteria count; Salmo. $=$ Salmonella spp. count; Pseudo. $=$ Pseudomonas spp. count; Entero. $=$ Enterococcus spp. count; THB = Total heterotrophic bacteria count; Clostr. = Clostridium spp. count; - = Not detected.

\section{Discussion}

In this study analyses made were for only thirty-one of the so many products sold. Those studied included two different mixtures each of preparations described as remedy for loss of appetite, anaemia, arthritis, asthma, diabetes mellitus and epilepsy. Preparations for cough and urinary retention were from three different producers, whilst dysmennorhoea and malaria were from four and five different producers, respectively.

The herbal preparations for loss of appetite, anaemia and arthritis were all found to be microbiologically safe to be used in this study. Products also found to be safe were asthma mixture A, cough mixturea $\mathrm{A}, \mathrm{B}$ and $\mathrm{C}$, diabetes mellitus mixture $\mathrm{B}$, dysmenorrhoea mixtures $\mathrm{B}$, $\mathrm{C}$ and $\mathrm{D}$, hypertension mixtures $\mathrm{B}$ and $\mathrm{C}$, and, malaria mixtures A, C and D. The rest of the products had one or two pathogens recorded in them and could not be recommended for usage.

Despite the increasing use of herbal medicine in many developing and industrialized countries [6,7] and the reported dependence of between $65 \%$ and $80 \%$ of the world's population on herbal medicines as their primary form of healthcare $[8,9]$, it cannot be fully integrated into the National Healthcare Scheme in Nigeria, if the orthodox medical doctors are not well disposed towards its use. Studies conducted among the Nigerian population have shown widespread use of traditional herbal medicine amongst hypertensive patients [36,37] and pregnant women [38]. The increasing use of these preparations could be as a result of the beliefs of patients in their efficacy, as well as the accessibility and affordability of the herbal medicaments. There is need however for appropriate regulation and standardization of herbal medicine use.

Early humans recognized their dependence on nature in both health and illness. Led by instinct, taste, and experience, primitive men and women treated illness by using plants, animal parts, and minerals that were not part of their usual diet. Physical evidence of use of herbal remedies goes back some 60,000 years to a burial site of a Neanderthal man uncovered in 1960 [39]. In a cave in northern Iraq, scientists found what appeared to be ordinary human bones. An analysis of the soil around the bones revealed extraordinary quantities of plant pollen that could not have been introduced accidentally at the burial site. Someone in the small cave community had consciously gathered eight species of plants to surround the dead man. Seven of these are medicinal plants still used throughout the herbal world [40]. All cultures have long folk medicine histories that include the use of plants. Even in ancient cultures, people methodically and scientifically collected information on herbs and developed well-defined herbal pharmacopoeias. Indeed, well into the 20th century much of the pharmacopoeia of scientific medicine was derived from the herbal lore of native peoples. Many drugs, including strychnine, aspirin, vincristine, taxol, curare, and ergot, are of herbal origin. About one-quarter of the prescription drugs dispensed by community pharmacies in the developed countries contain at least one active ingredient derived from plant material [41].

Products that recorded only presence of total heterotrophic bacteria, but values were greater than $50 \mathrm{cfu} / \mathrm{ml}$ can be used with caution.

Much unwritten knowledge resides in the hands of healers in many societies where oral transmission of information is the rule. Unfortunately, in many regions this information is endangered because there are no young apprentices to whom elderly healers can pass on their unwritten wisdom; the knowledge that has been refined 
over thousands of years of experimentation with herbal medicine is being lost. A major research opportunity in this area would be to catalog information on herbal medicines from thousands of traditional healers in cultures where these skills are normally transmitted through an apprentice system. Some organizations have recently increased their efforts to catalog endangered herbal knowledge from traditional medical systems in Latin America, such as those practiced in the rain forests of Belize [42].

Products such as loss of appetite mixture $B$, arthritis mixture $\mathrm{B}$, dysmenorrhoea mixture $\mathrm{D}$, malaria mixture $\mathrm{D}$ and urinary retention mixture A that did not record any microorganisms in all the tests carried out including absence of total heterotrophic bacteria must be viewed with suspicion since most of these products tend to be too acidic (i.e. $<\mathrm{pH} 4$ ) and can thus not support most bacteria growth, but can also cause stomach upset.

Herbs are not one-shot wonder drugs in the modern sense; rather, their effectiveness is based on gradual action to restore the natural balance of bodily functions that constitutes health. Very few plant remedies produce lasting beneficial effects after only one or a few doses; most treatments involve taking the remedy daily for at least several weeks. Their effectiveness is also greatly helped or hindered by ones overall life style, especially one's diet. A healthy diet and sufficient exercise to keep the body in good condition are valuable both for preventing much illness and for helping to overcome it when it does strike.

\section{Recommendations}

The only prepared remedies that can be kept for any length of time are ointments and those made with alcohol. The alcohol will preserve the later, and a little gum benzoin or tincture of benzoin (a drop per ounce of fat) will preserve salves or ointments made with a perishable base. Make infusions, decoctions, cold extracts, juice, poultices, and fomentations fresh each time. Whenever you do store any plant preparations, sterilize the containers before putting the preparations in them.

The solution to the quality control problem that exists in the developing world is for manufacturers and suppliers of herbal preparations to adhere to quality control standards and good manufacturing practices.

Consumers, health food stores, pharmacists, and physicians who use or sell herbal preparations should ask for information from the suppliers of herbal preparations on their quality control processes.

As more consumers, retailers, and professionals begin asking for quality control from the suppliers, it is possible more quality control processes will be utilized by the producers.

\section{Acknowledgements}

This investigation received financial support from the Government of Ghana. The authors would like to thank the Director-General of the Council for Scientific and Industrial Research of Ghana, the Director of the Water Research Institute and the Head of Environmental Biology and Health Division for their assistance. The cooperation and efforts of the staff of the Microbiology Section of the Water Research Institute are acknowledged.

\section{REFERENCES}

[1] A. A. Izzo and E. Ernst, "Interactions between Herbal Medicines and Prescribed Drugs: An Updated Systematic Review,” Drugs, Vol. 69, No. 13, 2009, pp. 1777-1798. doi:10.2165/11317010-000000000-00000

[2] N. R. Farnsworth, O. Akerele, A. S. Bingel, D. D. Soejart and Z. G. Guo, "Medicinal Plants in Therapy," Bulletion of the World Health Organization, Vol. 63, No. 6, 1985, pp. 965-981.

[3] E. Manheimer, S. Wieland, E. Kimbrough, K. Cheng and B. M. Berman, "Evidence from the Cochrane Collaboration for Traditional Chinese Medicine Therapies," The Journal of Alternative and Complementary Medicine, Vol. 15, No. 9, 2009, pp. 1001-1014. doi:10.1089/acm.2008.0414

[4] C. Gratus, S. Wilson, S. M. Greenfield, S. L. Damery, S. A. Warmington, R. Grieve, N. M. Steven and P. Routledge, "The Use of Herbal Medicines by People with Cancer: A Qualitative Study,” BMC Complementary and Alternative Medicine, Vol. 9, No. 14, 2009, p. 14.

[5] L. L. Dos Santos-Neto, M. A. de Vilhena Toledo, P. Medeiros-Souza and G. A. de Souza, "The Use of Herbal Medicine in Alzheimer's Disease-A Systematic Review," Evidence-Based Complementary and Alternative Medicine, Vol. 3, No. 4, 2006, pp. 441-445. doi:10.1093/ecam/nel071.

[6] A. Furnharm, "Why Do People Choose and Use Complementary Therapies?” In: E. Ernst, Ed., Complementary Medicine an Objective Appraisal, Butterworth-Heinemann, Oxford, 1996, p. 170.

[7] E. Ernst and A. White, "The BBC Survey of Complementary Medicine Use in the UK," Complementary Therapies in Medicine, Vol. 8, No. 2000, pp. 32-36.

[8] D. M. Eisenberg, R. B. Davis and S. L. Ettner, "Trends in Alternative Medicine Use in the United States, 19901997-Results of a Follow-Up National Survey,” Journal of the American Medical Directors Association, Vol. 280, No. 18, 1998, pp. 1569-1575. doi:10.1001/jama.280.18.1569

[9] World Health Organization, “Traditional Medicine,” 2007. http://www.who.int/mediacentre/factsheets/fs134/en/

[10] WHO, “The WHO Traditional Medicine Programme: Policy and Implementation,” International Traditional Medicine Newsletter, Vol. 1, No.1, 1985, pp. 1-5.

[11] O. A. Olajide, S. O. Awe, J. M. Makinde, A. I. Ekhelar, A. Olushola and O. T. Okpako, "Studies on the Anti-Inflammatory, Anti-Pyretic and Analgesic Properties of 
Alstonia Boonei Stem Bark,” Journal of Ethnopharmacology, Vol. 71, No. 1-2, 2000, pp. 179-186. doi:10.1016/S0378-8741(99)00200-7

[12] D. M. Eisenberg, R. C. Kessler, C. Foster, F. E. Norlock, D. R. Calkins and T. L. Delbanco, "Unconventional Medicine in the United States: Prevalence, Costs, and Patterns of Use," The New England Journal of Medicine, Vol. 328, No. 4, 1993, pp. 246-252. doi:10.1056/NEJM199301283280406

[13] J. Barnes, “Quality, Efficacy and Safety of Complementary Medicines: Fashions, Facts and the Future. Part 1. Regulation and Quality," British Journal of Clinical Pharmacology, Vol. 55 No. 3, 2003, pp. 226-233. doi:10.1046/j.1365-2125.2003.01810.x

[14] P. Gardiner, R. Graham, A. T. Legedza, A. C. Ahn, D. M. Eisenberg, and R. S. Phillips, "Factors Associated with Herbal Therapy Use by Adults in the United States," Alternative Therapies in Health and Medicine, Vol. 13, No. 2, 2007, pp. 22-29.

[15] S. S. Hasan, S. I. Ahmed, N. I. Bukhari and W. C. Loon, "Use of Complementary and Alternative Medicine among Patients with Chronic Diseases at Outpatient Clinics," Complementary Therapies in Clinical Practice, Vol. 15, No. 3, 2009, pp. 152-157. doi:10.1016/j.ctcp.2009.02.003

[16] K. Kraft, "Complementary/Alternative Medicine in the Context of Prevention of Disease and Maintenance of Health,” Preventive Medicine, Vol. 49, No. 2-3, 2009, pp. 88-92. doi:10.1016/j.ypmed.2009.05.003

[17] A. A. Modi, E. C. Wright and L. B. Seeff, “Complementary and Alternative Medicine (CAM) for the Treatment of Chronic Hepatitis B and C: A Review,” Antiviral Therapy, Vol. 12, No. 3, 2007, pp. 285-295.

[18] E. Mendes, M. T. Herdeiro and F. Pimentel, "The Use of Herbal Medicine Therapies by Cancer Patients," Acta Médica Portuguesa, Vol. 23, No. 5, 2010, pp. 901-908.

[19] M. Oktem, D. Eroglu, H. B. Karahan, N. Taskintuna, E. Kuscu and H. B. Zeyneloglu, "Black Cohosh and Fluoxetine in the Treatment of Postmenopausal Symptoms: A Prospective, Randomized Trial," Advances in Therapy, Vol. 24, No. 2, 2007, pp. 448-461. doi:10.1007/BF02849914

[20] A. Q. Pham, H. Kourlas and D. Q. Pham, "Cinnamon Supplementation in Patients with Type 2 Diabetes Mellitus,” Pharmacotherapy, Vol. 27, No. 4, 2007, pp. 595-599. doi:10.1592/phco.27.4.595

[21] M. Shimazaki and J. L. Martin, "Do Herbal Agents Have a Place in the Treatment of Sleep Problems in Long-Term Care?" Journal of the American Medical Directors Association, Vol. 8, No. 4, 2007, pp. 248-252. doi:10.1016/j.jamda.2006.11.001

[22] S. Shrestha, H. C. Freake, M. M. McGrane, J. S. Volek and M. L. Fernandez, "A Combination of Psyllium and Plant Sterols Alters Lipoprotein Metabolism in Hypercholesterolemic Subjects by Modifying the Intravascular Processing of Lipoproteins and Increasing LDL Uptake,” The Journal of Nutrition, Vol. 137, No. 5, 2007, pp. 11651170.

[23] H. A. Tindle, R. B. Davis, R. S. Phillips and D. M. Eisenberg, "Trends in Use of Complementary and Alter- native Medicine by US Adults: 1997-2002,” Alternative Therapies in Health and Medicine, Vol. 11, No. 1, 2005, pp. 42-49.

[24] N. W. Crawford, D. R. Cincotta, A. Lim and C. V. Powell, "A Cross-Sectional Survey of Complementary and alternative Medicine Use by Children and Adolescents Attending the University Hospital of Wales," BMC Complementary and Alternative Medicine, Vol. 6, No. 1, 2006, p. 16.

[25] S. Joos, B. Musselmann, A. Miksch, T. Rosemann and J. Szecsenyi, "The Role of Complementary and Alternative Medicine (CAM) in Germany-A Focus Group Study of GPs,” BMC Health Services Research, Vol. 8, No. 7-8, 2008, p. 127. doi:10.1186/1472-6963-8-127

[26] S. Hori, I. Mihaylov, J. C. Vasconcelos and M. McCoubrie, "Patterns of Complementary and Alternative Medicine Use amongst Outpatients in Tokyo, Japan,” BMC Complementary and Alternative Medicine, Vol. 8, No. 1, 2008, p. 14. doi:10.1186/1472-6882-8-14

[27] B. M. Berman, B. K. Singh and L. Lao, "Physicians' Attitudes towards Complementary or Alternative Medicine: A Regional Survey," The Journal of the American Board of Family Practice, Vol. 8, No. 5, 1995, pp. 361-363.

[28] J. A. Astin, A. Marie and K. R. Pelletier, “A Review of the Incorporation of Complementary and Alternative Medicine by Mainstream Physicians," Archives of Internal Medicine, Vol. 158, No. 21, 1998, pp. 2303-2310. doi:10.1001/archinte.158.21.2303

[29] B. M. Berman, B. B. Singh, S. M. Hartnoll, et al., "Primary Care Physicians and Complementary Alternative Medicine: Training, Attitudes, and Practice Patterns,” The Journal of the American Board of Family Practice, Vol. 11, No. 4, 1998, pp. 272-281.

[30] R. D. Crock, D. Jarjoura and A. Polen, “Confronting the Communication Gap between Conventional and Alternative Medicine: A Survey of Physicians' Attitudes," Alternative Therapies in Health and Medicine, Vol. 5, No. 2, 1999, pp. 61-66.

[31] M. M. Tabi, M. Powell and D. Hodnicki, "Use of Traditional Healers and Modern Medicine in Ghana," International Nursing Review, Vol. 53, No. 1, 2006, pp. 52-58. doi:10.1111/j.1466-7657.2006.00444.x

[32] C. Abel and K. Busia, “An Exploratory Ethnobotanical Study of the Practice of Herbal Medicine by the Akan Peoples of Ghana,” Alternative Medicine Review, Vol. 10, No. 2, 2005, pp. 112-122.

[33] A. Sali and L. Vitetta, "Integrative Medicine in Gynaecological Cancers,” Australian Family Physician, Vol. 36, No. 3, 2007, pp. 135-136.

[34] A. A. Sittie, "Quality Assessment. In a Manual of Harmonized Procedures for Assessing the Safety, Efficacy and Quality of Plant Medicines in Ghana,” Yamens Press Ltd., Accra, 2005.

[35] S. C. Lenore, E. G. Arnold and D. E. Andrew, "Standard Methods for the Examination of Water and Wastewater," American Public Health Association, Washington DC, 1998.

[36] C. O. Amira and N. U. Okubadejo, "Frequency of Com- 
plementary and Alternative Medicine Utilization in Hypertensive Patients Attending an Urban Tertiary Care Centre in Nigeria," BMC Complementary and Alternative Medicine, Vol. 7, No. 1, 2007, p. 30.

doi:10.1186/1472-6882-7-30

[37] P. E. Osamor and B. E. Owumi, “Complementary and Alternative Medicine in the Management of Hypertension in an Urban Nigerian Community," BMC Complementary and Alternative Medicine, Vol. 10, No. 1, 2010, pp. 36. doi:10.1186/1472-6882-10-36

[38] T. O. Fakeye, A. R. Rasaq and I. E. Musa, “Attitude and Use of Herbal Medicines among Pregnant Women in Nigeria,” BMC Complementary and Alternative Medicine, Vol. 9, No. 1, 2009, pp. 53-60. doi:10.1186/1472-6882-9-53
[39] R. S. Solecki, “Shanidar IV, a Neanderthal Flower Burial of Northern Iraq,” Science, Vol. 90, No. 4217, 1975, pp. 880-881.

[40] D. Bensky, A. Gamble and T. J. Kaptchuk, "Chinese Herbal Medicine: Materia Medica,” Revised Edition, Eastland Press Inc., Seattle, 1993.

[41] N. R. Farnsworth, O. Akerele, A. S. Bingel, D. D. Soejart and Z. G. Guo, "Medicinal Plants in Therapy," Bulletion of the World Health Organization, Vol. 63, No. 6, 1985, pp. 965-981.

[42] R. Arvigo and M. J. Balick, "Rainforest Remedies: 100 Healing Herbs of Belize,” Lotus Press, Twin Lakes, 1993. 